\section{Ant Addres:}

\section{THE INFLUENCE OF THE BRITISH IIEDICAL ASSOCIATION IN THE ESTABLISHMENT OF OPHTHALMOLOGY AS A SPECIAL SCIENCE.}

Delivered before the Section of Ophthalmology of the Annual Meeting, Brighton, 1913.

BY

THOMAS H. BICKERTON,

OPHTHALMIC SURGEON, LIVERPOOL ROYAL INFIRMARY; PRESIDENT OF THE SECTION.

Gentlemen,-Duty and pleasure are not always synonymous terms, but on the present occasion, in offering a welcome to the members of the Ophthalmological Section, I. find them to be so.

Before entering on the business of the Section, I must express my cordial thanks to those who have placed me in the position of President. I appreciate to the full the honour thus conferred, and wish I could more adequately express my acknowledgements. Our programme of papers and subjects for discussion promises great things for the interest and success of this meeting, and instead of asking you to listen to an address on any special subject in ophthalmology I propose to dwell on the practical serrices rendered to oplithalmic work by the British Medical Association.

This idea was suggested by noticing that the date of the founding of the Sussex and Brighton Eye Hospital coincided with that of the founding of the Association, namely, 1832. It is certain that the methods of treatment in use in that hospital to-day, differ as greatly from those existing then as do our ordinary conditions of life. Yet, in point of time, it is not so very long ago, and there will undoubtedly be in this health resort inhabitants who were living when the foundation stone was laid. While it is difficult to think oneself back in the general surroundings of that period, it is not more so than to realize the position of medicine and surgery at that time. But we cannot estimate our indebtedness to the Association otherwise.

The Position of the Medical Profession in 1832.

Chaos is the only word which will describe the position of the profession in those days. The public had no means of distinguishing between qualified and unqualified practitioners. The grossest anomalies prevailed with regard to the licensing bodies. Graduates of English universities could practise anywhere in Englaud, except in London and seven miles around, in Wales, in Scotland, and in Ireland, except Dublin; while, on the other hand, graduates of Irish and Scottish universities wishing to practise in England or Wales were obliged to graduate again at an Euglish university or take the licence of the English College of Physicians. Grievances and inequalities, the evils of a rampant quackery and illegal practice, which ever evaded the arm of the law, the entire absence of uniformity in the regulations for medical study, the variety in the value of diplomas, engendered in the ranks of the profession jealousies, antipathies, and hostilities, fortunately unknown to-day.;

The medical profession was literally a "house divided against itself." The respective professions of physician, surgeon, apothecary, druggist, and chemist were all soverely separate and distinct from each other.

\section{Ophthalmology in the First Quarter of the} Nineteenth Century.

In order to realize the influence of our Association on o hithalmology it is necessary to review the records concerning the treatment of diseases of the eye prior to and at the beginning of the nineteenth century. For this

* Iny one intrested in racalling the situation will find it in IRivington's Slietch of the History of the Medical Profession of the United Kingdom. we need only refer to medical authors and to the advertisement pages of the newspapers of that date. I have sought among the writings of men distinguished for their learning, whose position and reputation in the eycs of their professional brethren was unassailable.

Of these, perhaps, the best known is Sir William Lawrence, F.R.S., Surgeon-Extraordinary to the Queen. Lawrence was appointed surgeon to the London Hospital for Diseases of the Eye-now the Royal London Ophthal mic Hospital-in 1814, nine years after it was opened, and was senior surgeon to that hospital when he retired. $\mathrm{He}$ was, in addition, surgeon to St. Bartholomew's Hospital, and lecturei on surgery at that hospital; also surgeon to Bethlem and Bridewell Hospitals. In his introduction to his Treatise on Diseases of the Eye, published in 1833, ho says:

As the general body of surgeons did not understand diseases of the eye, the public naturally resorted to oculists, who, seeing such cases in greater numbers, became better acquainted with the symptoms, diagnosis, and treatment, and especially more skilful in the operative department. At the same time, the subject, being imperfectly understcod, was neslected in the general surgical courses, in which many important affections of the eye were entirely unnoticed and the whole inadequately explained. Thus students who resorted to London for the completion of their medical studies had really no means of learning this important department of the profession, which was tacitly abandoned, eron by the hospital surgeons, and turner? over to the oculists. 'The latter, not being conversant with the principles derived from anatomy, physiology, and general pathology, attended merely to the organ, and relied almost exclusively on what is comparatively of little importanceexclusively on what is comparatively of little importancedismembered from the general science, was reduced to a very low.ebb. Until within a few years it was, in this country at least, in a state of almost total darkness.

Our second source of information-advertisementsaffords abundant confirmation of the distinguished surgeon's statement. 'Thus :

Edinburgh, December 28. Professor Hillmer, Physician and Counsellor of the Court to the King of Prussia, has restored many blind people to their sight, in presence of the gentlemen of the faculty, who express their highest approbation of the of the faculty, who express their highest approbation of the
great perfection to which this gentleman has brought this most noble and useful science. The charitable and hovest behaviour of this worthy man and the great success his inimitable performances are attended with (far superior to anything ever before introduced into these Kingdoms) make him universally esteemed and beloved. It is very remarkable that this gentleman's operations are attended with no pain or inflammation, and none of them miscarried.-Williamson's Licerpool Advertiscr, December, 1758 .

They write from Chester that a few days since arrived at the Talbot Inn in that city, from Bath, on his way to Dublin, the Chevalier 'Taylor, Ophthalmiate to his present Majesty, and their Imperial Mrajesties to the Kings of Holland Denmark, Sweden, etc., to All the Electors of the Holy Empire, etc., who; after having been in every Kingdom, Province, State and City of the least consideration-in every Court-presented to every crowned Head and Sovereign Prince in all Europe without exception, is lately returned to England, with a view of establishing his residence in London.-In various parts there appears of his writings, in many languages, no less than 44 works on the Eye and its defects; the produce of greatest experience and practice so extensive, that for many rears near 4,000 persons practice so extensive, that for many rears near 4,000 persons
have been yearly undei his care for defects of sight in different harts of the world.-At Exeter have been lately published the names and habitations of upwards of 140 persons who have been restored to sight by his aid, within these few weeks, in that city and neighbourhood.- A great number of persons affected in the eye are now attending him at Chester from varions parts. And we can assure our reaclers, that to-morrow erening he will certainly come to the Talbot Inn in Liverpool, and will continue till Monday evening; on Tuesday evening next will return to Chester, and on Wednesday will proceed to the Head for Dublin: during his short stay, the poor as in all places shall have his best assistance without expense.-IVilliamson's Licerpool Adrertiser, January 12th, 1759, p. 2, col. 3.

Having had an extraordinary cure performed on one of my children, who was born blind, by Baron de Wenzel, Occulist to His Britannic Majesty in Pall Mall; I am induced to make the circumstances public, for the benefit of any person in the same case. The child continued blind with cataracts on both eyes till last year, when (as he was then four years old), I applied to the Baron to extract them. He performed the operation on the right eye, and had much greater success than I could have expected, as the sight is perfectly obtained; within these few days the same operation has been repeateil on his left eye, days the same operation has been repeated on his left eye,
which is already in so fair a way that I doubt not but a short which is already in so fair a way that I doubt not but a short
time will make this as satisfactory a cure as the other. As many persons who may see this may be unacquainted with the nature of the operations performed by the Baron, and may wish for fnrther information; I shall be happy to answer any 
more particular enquiries, and shall think myself fortunate if I am the means of putting any one in the way to procure relief in so valuable a part as the eye. Signed,

S. BOSANQUET

(Late one of the Directors of the Bank, Forest House, Near Lavton, Essex).

-Williamson's Liverpool Advertiser, July 22nd, 1773.

Mons. Pellier, Occulist (before his departure for London, where he intends to fix his residence), proposes to spend a short time in this town, during which the afflicted with disorders in the eyes may have recourse to him.

Mons. Pellier was here last year, when he performed many successful operations in presence of gentlemen of the Faculty, in this town. He cures Mrs. Hargreaves, seventy years of age, No. 32 Matthew Street; Mrs. Pott, wife of Mr. Pott, sugarboiler, No. 14, in Castle Street; Robt. Christie, Musician, 23 years of age, who was blind many years; a person at No. 44 George's Street, and several others.-Willian!son's Liverpool Adiertiser, October 20th, 1785.

The skill of this oculist was vouched for by the physicians and surgeons of the Liverpool Infirmary and of the Liverpool Dispensary. Park and Alanson were two of the most notable surgeons of that day.

We, the undersigned physicians and surgeons, having seen M. Pellier operate on the cataract, and having conversed with him on the subject of his professicn as an oculist, approve much of his dexterity in operating, and judge favourably of his knowledge in diseases of the eye.

Edward Alanson, Surgeon to the Liverpool Infirmary.

Henry Park, Surgeon to the Liverpool Infirmary.

R. Blundell,

J. Tetlow,

James Gerard, Physician to the Liverpool Infirmary.

T. Houlston, Physician to the Liverpool Infirmary.

J. Binns, Physician to the Liverpool Dispensary.

J. Worthington, Physician to the Liverpool Dispensary.

John Lyon, Surgeon to the Liverpool Infirmary.

-Williamson's Liverpool Advertiser, October 21st, 1784.

Oculists were obviously necessary, and the public preferred a man who devoted himself exclusively to diseases of the eye, treatment at this time being practically limited to external affections and cataract.

Travers, writing in 1820, remarks that "no one except the thorough surgeon can make the complete oculist"the qualification distinguishing him (the "complete oculist "), in the writer's mind, from the "bare oculist." But he omitted to state where the complete oculist was to obtain his knowledge. Certainly not in the schools of anatomy, as a brief reference to them will disclose, and it is seen that the net result of teaching or no teaching was the same-with this difference, that the general surgeon ceased to take interest in eye work, and it was consequently left to the unqualified man (the bare oculist), who became the skilful operator.

In the year 1815 there were in England only six schools of anatomy (except those of Oxford and Cambridge). In this year the Apothecaries Act was passed. In 1828 there were twenty schools in which anatomy was taught and dissections carried on-namely, 12 in London and 8 in the provinces-at Manchester 3, Liverpool 2, Birming. ham 1, Bristol 1, Sheffield 1.

Increase in the number of anatomical schools did not materially benefit the student. Though premises were now licensed, subjects for dissection were not available unless illegally obtained through the medium of the bodysnatcher. Even in Edinburgh, a recognized centre, wo read: "The average number of medical students in Edinburgh is 700 each session. For some years past the difficulty of procuring subjects has been so great that out of that number not more than 150 or 200 harc ever attempted to dissect." Students, therefore, betook themselves to the Continental schools, where the facilities wero greater, and one writer suggested "that all medical students will go abroad if an alteration is not soon made." In this condition of things the teaching of the anatomy of special organs was practically nil, and the distinction between the "complete oculist" and the "bare oculist" was academic.

Previous to the year 1817 no lectures were delirered in Great Britain on the diseases of the eye; a knowledge of these complaints was not presumed to form part of the education of a surgeon. Subsequently lectures were given at the Royal Westminster Ophthalmic Hospital.

The information imparted is on record. The lecturer first states that public opinion, though for the most part founded on professional anthority, is generally wrong.
Public opinion, he continues, pronounces the eye to be an organ of a very delicate nature, exquisitely sensible, requiring the greatest delicacy of touch and the utmost nicety of management; but students must be taught otherwise. They must learn that the eye is not a delicate organ, that it will suffer more comparative violence with less injury than any other of importance in the bodyone would like to know which he considered the other important organs-and that the ablest and most successful operators are neither the most gentle nor the most tender in their proceedings.

Difficulties, he goes on, supposed to attend the performance of operations on the eye, did not exist. "Few persons can duly estimate the liberties that may be taken with the eye until they have seen several operations performed." Peculiar tact, he said, was supposed to be necessary to perform operations on the eye with advantage, "But students must not suffer themselves to bo deceived, a surgeon who could operate well on any other part of the body, possesses coolness enough to operatc upon an eye, the loss of which is comparatively of little consequence."

These unique sentiments are those of a "complete oculist," other'wise "surgeon," and later Fellow of the Royal Society; they were published by him for the purpose of assisting in bringing the management of diseases of the eye within the principles which regulate the practice of surgery in general. Is it wonderful that the public preferred the "bare oculist"?

Foundation of Special Hospitals.

Lack of interest in eye work is explained by lack of facilities. Prior to 1832 there were only three officially recognized special establishments for treatment of affections of the eye-the London Iispensary for Curing Diseases of the Eye and Ear (Royal London Ophthalmic Hospital), suggested October lst, 1804, by John Cunningham Saunders, opened March 25th, 1805, but not thrown open to students till 1810; the Royal Infirmary for Diseases of the Eye, Cork Street, opened 1804; and the Westminster Ophthalmic, in 1816. Not until 1824 did an eye department exist in connexion with any of the London hospitals. The first eye infirmary in the provinces-the third established in Great Britain for treating diseases of the eye exclusively - was at Exeter in 1808, and we read that the efforts of a professional combination to prevent the formation of the West of England Infirmary for Curing Diseases of the Eye was only defeated by the founder-Mr. (later Sir William) Adams-having previ. ously obtained the sanction and patronage of His Royal Highness the Prince Regent.

This "First Gentleman of Europe" did much for Brighton, but though we find little to admire in his life and character, we cannot quite agree with Leigh Hunt's indictment of him as a man who "had just closed half a century without one single claim on the gratitude of his country or the respect of posterity," for we remember that he performed at least this one good action during his lifetime. The special hospitals were founded in the following order :

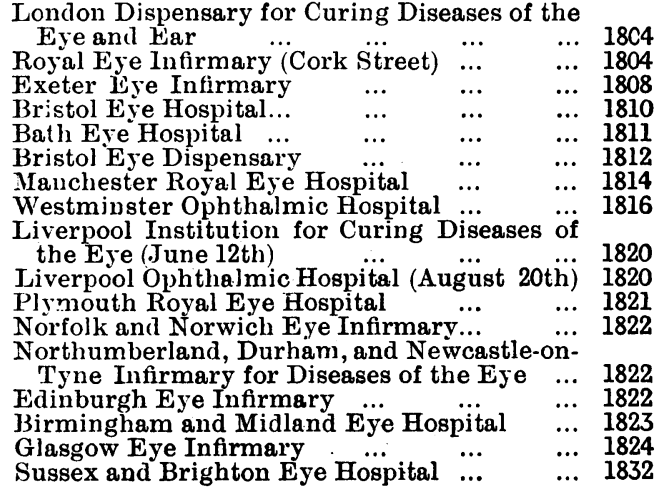

The last mentioned owes its establishment to Mr. J. B. Slade, M.D., who, seeing that " an institution intended exclusively for the cure of ophthalmic diseases was much needed in this town," enlisted the help and sympathies first of his medical friend, Mr. James Pickford, and after. 
wards those of their private friends and Dr. Todd. The "Infirmary" was publicly instituted on August 27th, 1832, the example of Exeter Eye Hospital being instancedpossibly the action of the Prince Regent in that case had a reflex action here. It is interesting to note that among the appointments on the staff was that of a "cupper." The Patron was his Grace the Duke of Richmond, the

President the Most Noble the Marquis of Bristol.

Of the thirty-seven English counties, excluding Middlesex and Monmouth, only eight possessed eye hospitalsnamely, Devonshire (one), Gloucestershire (two), Lancashire (three), Norfolk (one), Northumberland (one), Somersetshire (one), Sussex (one), Warwickshire (one). There were two for the whole of Scotland-the Edinburgh Eye Dispensary (1822) and the Glasgow Eye Infirmary (1824) - while Ireland possessed none.

Principal Ophthalmic Works prior to 1832

A list (published in 1846) of the principal works on ophthalmic medicine and surgery published in the English language before 1832, gives the names of seven authors:

1808. J. Wardrop: The Morbid Anatomy of the Human Eye. First edition. Edinburgh.

1811. J. C. Saunders: A T'reatise on some Practical Points relating to the Diseases of the Eye. First edition. London.

1814. W. Adams: Practical Observations on Diseases of the Eye. First edition. London.

1820. J. Vetch: A Practical Treatise on the Diseases of the Eye. First edition. London.

1820. B. Travers: A Synopsis of the Diseases of the Eye and their T'reatment. First edition. London.

1822. A. Watson: A Description of the Diseases of the Eye. First edition. Edinburgh.

1823. G. J. Guthrie: Lectures on the Operative Surgery of the Eye. First edition. London.

Why A Practical Treatise on Diseases of the Eye, by W. Mackenzie of Glasgow, published 1830, is omitted I know not. Of journals devoted to ophthalmic work there were none.

Medical Societies prior to 1832.

Though medical societies existed both in London and in the provinces, they were not formed with the intention of uniting the profession. They were entirely local.

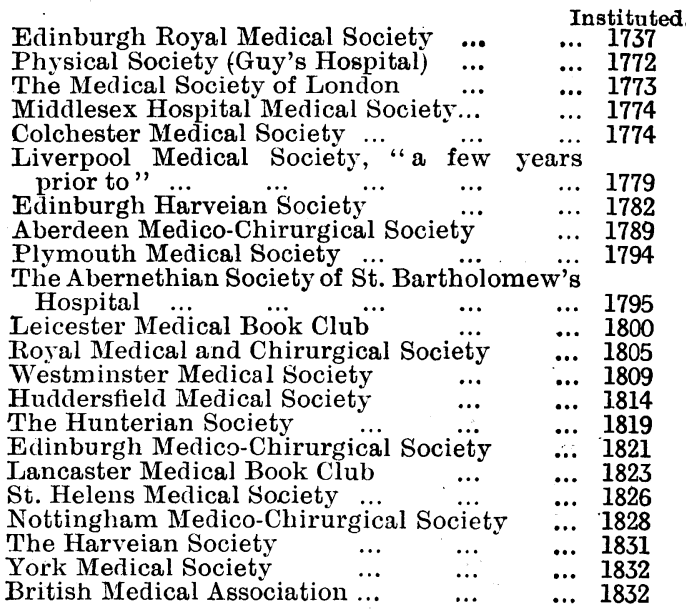

The rules governing the Plymouth Medical Society are possibly not representative of all :

1. Society to consist of fifteen members only.

2. Society to meet at 7.o'clock on the Friday nearest to full moon.

3. Society to meet at members' houses in rotation.

4. Society to promote friendly intercourse and good feeling.

5. Society to circulate books on medicine.

6. Society to meet and dine every three months.

7. Every member was expected to be present at the dinner.

Dinners were evidently characteristic of the times, and much appreciated, for in 1829 it was suggested that two stomach pumps should be purchased, indicating that the dinner did not fall short of a mayoral banquet. Proposition not carried, inasmuch as every medical practitioner was expected to have a stomach pump of his own. Society accepted no excuse for absence. In 1822 membership reduced to twelve.

The British Medical Association was founded on July 19th, 1832, having for its main object the congenial union of scientific research and professional honour, and the diffusion and increase of medical knowledge in every department of science and practice.

How consistently the desire of Sir Charles Hastings has been kept in view and furthered members who possess the Transactions and Journals can testify. A complete set of these constitutes a medical library. Its pages are a treasury of knowledge. In the medical as in the other sciences the press is one great means of advancement. Through this mighty engine only can discoveries become extensively diffused, which affords the best security for further developments.

From its formation the Association was alive to the needs of ophthalmology.

The first volume of Transactions (1833) contains a full report of the Birningham Infirmary for Diseases of the Eye, by Richard Middlemore, with special observations on : (a) Small-pox pustule of the cornea ; $(b)$ conical cornea; (c) quinia in strumous affections of the eye-which treatment he was the first to propose and adopt; (d) hydrophthalmia ; (e) strychnia in amaurosis.

The following, signed "W. Hetling," also appears in this volume:

... take leave to congratulate the members of the Association on the production of its first volume; and facilities which the establishment of this institution will afford for the more rapid and extensive communication of medical information among the profession generally. It is hoped that the reflection of how much information has been lost, and suffered to run to waste, for want of a general dépôt, which might have afforded a durable asylum and existence to valuable facts and observations, will animate the provincial profession to see their real interest and dignity in their true light.

Association and publication are the simple elements of our new-formed society, which, I trust, will, both in its infancy and future growth, be emulous of being worthy to share, in the future growth, be emulous of being worthy to share, in the polis, and that it will ever study to cultivate and extend their well-designed improvements, for the honour of the profession and the benefit of mankind.

The second volume of the Transactions contains full reports of the same infirmary, with critical observations on : (a) Disease of, or changes in, the tarsal cartilages, as connected with chronic conjunctivitis; (b) staphyloma; (c) rheumatic sclerotitis; $(d)$ dislocation of the lens; (e) hydrophthalmia; $(f)$ on the occasional effects of tumours in the eyelids.

The third volume contains an exhaustive article on pterygium (27 pages), also report of Birmingham Eye Infirmary. with ubservations on: (a) Development of the cornea; (b) opacity of the cornea; (c) staphyloma; $(d)$ cataract; $(e)$ amaurosis-strychnia; $(f)$ inflammation of semilunar membrane.

T'ime will not permit any detailed inquiry; it will suffice to say that it would be difficult to find a volume in which some phase of the anatomy, physiology, pathology, or treatment of the eye does not receive attention either in the form of special articles or reviewed in the retrospective annual addresses.

The idea of forming local Branches of the Association was first mooted in 1835. In that year an Eastern Provincial Medical and Surgical Association was formed at Bury St. Edmunds for the counties of Cambridge, Norfolk, Suffolk, and Essex. The founders contemplated the possibility of amalgamation with the Provincial Medical and Surgical Association instituted at. Worcester, and this project was carried through in the following year-1836when branches were also formed at Wells, Bath, and Southampton.

The Association assumed the name British Medical Association in 1856, and from an early date there were Branches in the Colonies. The exact date of the foundation of the first colonial Branch I do not know. The official dates given in the list of members refer to formal recognition after reconstitution.

It is clear that from a very early stage of the Association the idea of local medical organizations linked into a national, and finally into an imperial, organization was present in the minds of the founders. 
Ophthalmic Journals.

We read that in 1836 "an ophthalmic journal has just been proposed by Mr. Middlemore"; but prior to 1865apart from hospital reports-there was no English journal exclusively devoted to ophthalmology.

In the year 1865 an attempt was made to remedy this defect by the issue of the Ophthalmic Review, edited by J. Z. Lawrence, of London, and Thomas Windsor, of Manchester. This publication was modelled upon the well-known Annales d'Oculistique and the Monatsblätter of Zehnder. It died in infancy. Its pages indicate the cause. There were people who believed that ophthalmo. logy, like charity, should begin at home-and stop there.

The Transactions and Journal of the British Medical Association had been in existence thirty-five years before the general London hospitals began to open eye departments; Guy's was the one exception, establishing a department in 1824. Similar departments were opened in the following order :

King's College Hospital

London Hospital (Whitechapel) $\quad \ldots \quad \ldots \quad \ldots 1866$

St. George's Hospital

St. Bartholomerw's ...

St. Thomas's

Westminster Hospital

Charing Cross

Unfortunately I have not the same information as to Middlesex and St. Mary's.

Up to and including the year 1866, all papers, whatever the subject, were taken in the general meeting of the Association. In this year discussions on special subjects were arranged. Vose Solomon, at the Worcester meeting (vide British Medical Journal, 1882, vol. ii, p. 271) of 1882, stated in his address that when the Association met at Cambridge (1864) a proposal was made, "unhappily without effect," that an address should be given on ophthalmology.

In 1867 Sections were established in four subjectsMedicine, Surgery, Midwifery, and physiology. Thereafter, papers on the eye were read in the Surgical Section. Ten years later (1877) the number of Sections was sixnamely, Medicine, Surgery, Obstetric Medicine, Public Medicine, Physiology, and Psychology.

Wheelhouse, of Leeds, in his review of the progress of surgery, delivered at the Bath annual meeting, in 1878, while strongly condemning specialities in surgery, made a notable exception in the case of ophthalmic surgery. His words were:

I am in no sense a specialist; indeed, desirous as I am to record my opinion that specialities in surgery are distinctly disadvantageous, I yet feel bound to exempt ophthalmic surgery altogether from such condemnation; the field is so large, the altogether from such condemnation; the field is so large, the
tissues involved are so numerous, the operative procedures required so delicate in their character, that it is well, in my judgement, that ophthalmic surgery has been erected into a special science; and with the acknowledgement to those in my audience who have electeil to devote themselves to the study of this branch of surgery, that, in no portion of the whole field of our art, has greater activity been shown, or greater advance been made, I will dismiss the subject.

In these words we find endorsement of the wisdom of the ancients: (in Persia and Egypt) in requiring that oculists should be a separate class and ophthalmology a special science.

The objection of British surgeons to recognize specialism, so openly and strongly expressed in the first quarter of the nineteenth century, was at last breaking down. But the subject was not dismissed. While the benefit to medical science, to the profession, and to the priblic, of this now established custom was admitted, simple recognition of the need was not sufficient. Education of the student in the groundwork of ophthalmology was essential. In large towns the services of skilled eye men could always be obtained, but in small towns and in the country this was not so, the practitioners, otherwise skilful, not having had any teaching in ophthalmic work.

Upon recognition of this fact, it followed that practical means should be taken to meet the necessity. It was considered by the Editor of the British Medical Jourial that the best remedy would be to make a three months' course of lectures upon ophthalmic surgery, with three months' attendance at an ophthalmic clinic, compulsory by the licensing bodies (British Medical Journal, 1878, vol. ii, p. 963).
At a General Council meeting, March 26th, 1879, Mr. Teale presented a memorial, signed by twenty-two of the leading ophthalmic surgeons in London, in which they drew attention to the advisability of making it compulsory upon all medical students to attend a three months' course of practical ophthalmology, either at the special eye department of a general hospital or at a special ophthalmic hospital, as well as a course of twenty lectures on ophthalmology at the least; and to the importance of making ophthalmology form a distinct subject of exam1nation at the Pass examination for surgical diploma or at the examination of a conjoint board* (BRITISH MEdICAL Journal, 1879, vol. i, p. 522).

At this time the only diploma in the United Kingdom for which a certificate of attendance upon ophthalmic surgery was required was that of Bachelor in Surgery of Trinity College, Dublin.

It logically followed that a special science deserved a special section, and in the following year (1879) at the Annual Meeting held at Cork, a subsection-Ophthalmology and Otology - of the Surgical Section was for the first time accordingly formed. Mr. Jonathan Hutchinson was chairman, and H. R. Swanzy, Dublin, and E. Nettleship, London, were secretaries. Discussions on the following set subjects were arranged:

Treatment of glaucoma, by $\mathrm{H}$. Power

Examination for colour blindness, H. R. Swanzy and Professor Hermann Cohn, of Breslau.

Use of eserine, pilocarpin, etc., Macnaughton-Jones.

Treatment of detached retina, Shadford Walker.

Tobacco and alcoholic amblyopia, Hirschberg, Berlin.

Diphtheritic ophthalmia, Nettieship.

In addition, no fewer than eleren other papers on diseases of the eye were promised.

The success of this new departure was so pronounced that a resolution was passed by the ophthalmic surgeons urging the desirability of an annual Ophthalmic Section. In December, 1879, the formation of such a Section was determined upon by the Council of the British Medical Association.

In the early part of 1880 (February) the formation of an Ophthalmological Society was suggested. While it cannot be definitely stated that this society owed its origin to the impetus given to ophthalmic work, by the action of tho British Medical Association in forming a special Section, by the unqualified success which attended the work of the Section, and by the unanimous request of the ophthalmic surgeons present for the establishment of an annual Oplithalmic Section, it is a coincilence that five of the most prominent members of the 1879 meeting (Cork) were members of the first council of the new society.

Personally, I am inclined to look a little further back, and find the motive power in the notable speech delivered by Mr. Wheelhouse, at Bath, on August 8th, 1878.

In 1880, the annual meeting took place at Cambridge, and for the first time a special Section in Ophthalmology was formed. The first President was $\mathrm{Mr}$. W. Bowman; Vice.Presidents, Mr. Henry Power and Mr. H. R. Swanzy; Secretaries, Dr. W. A. Brailey and Dr. David Little (British Mejical Journal, 1880, vol. ii, p. 228). The subjects for discussion were (1) the nature of glaucoma (2) toxic amaurosis, especially in relation to colour peiception. In addition, the number of papers promised was thirty-six. Prior to the formation of the subsection in 1879, the number was five or six.

An analysis of the personnel of the British Medical Association Ophthalmological Section is not without interest, for it shows that all were members of the first Council of the Ophthalmological Society. Of 22 members of the first Council of the Ophthalmological Society 14 took an active part in the work of the Section, 12 of them reading papers. Mr. William Bowman was the President of both.

This is the third meeting of the Association in Brighton. The first was in 1851, a year memorable for the discovery of the ophthalmoscope, and for the removal of an eye for injury.

* The licensing bodies on being consulted replied almost unanimously "that it would not be desirable either to require attendance ophthalmic surgery a distinct subject of examination" to make MEDICAL JodRNAL, 1880, vol. ii). 
In 1886 the second meeting took place. The year is memorable for the discovery of cocaine. I remember the meeting well, it being the first I had visited; and it is sad to think that one half of the members who took an active part in the work of the Section, are dead, including my old friend of Moorfield's days-A. H. Benson, of Dublin.

In two respects at least, points of similarity may be noted between the last and the present meeting. That meeting clashed with the Heidelberg Ophthalmological Congress, while the forthcoming International Medical Congress in London deprives us of the pleasure of seeing many colleagues.

Of the topics for discussion on this occasion, two were dealt with in 1886-one under the heading, "What is the best method of dealing with a lost eye?" the other being, "The use of styles in the treatment of epiphora."

Such is a slight sketch of the records of our Association with regard to our particular branch of the profession up to about the time of the last annual meeting beré. What has been done in and for ophthalmology during the last twenty years will be within the knowledge of all members present.

If I interpret these records correctly, it is obvious that the Association has, through the medium of its annual meetings and its weekly Journal, ever at hand, done great service to ophthalmology, and it is right that honour should be given where honour is due.

I have always felt that the Association has never yet had the credit due to it for the stimulus it has afforded to the study of clinical and scientific nedicine, and I am glad to have this opportunity of acknowledging my personal indebtedness.

Almost every privilege which our branch of the profession possesses to-day is due to the British Medical Association, and every member should be a loyal and active supporter of it.

THE Royal Victoria Infirmary, Newcastle, is the recipient under the will of the late Dr. John George Fenwick of a bequest of $£ 50,000$, in addition to a legacy of $£ 1,000$. The testator, who was formerly a partner in a private bank operating in Newcastle, directed that while the small sum could be used for general purposes, the larger, which was to be paid to the institution duty free, should be held in trust as an endowment fund. The hospital has 430 beds, its annual expenditure being about $£ 37,000$ a year.

A STATISTICAL return (Feeble-ninded Persons under the Poor Law, H.M. Stationery Office, 307, price $2 \frac{1}{2} \mathrm{~d}$.) relating to all persons in England and Wales who on July 20th, 1912, were in receipt of one or other form of Poor Law relief, and who were deemed to be mentally defective but had not been certified as insane, has recently been presented to the House of Commons. The total number was 31,824 persons, of whom 2,340 were children. Over 33 per cent. of the adults were aged 60 and upwards, and over 57 per cent. were women; of the latter nearly 60 per cent. were single women without children, while the ratio of single women with children to the total number of women was 7.5 per cent. Taking the whole number of defectives, about 24 per cent. were in receipt of outdoor relief, but in the case of the children, all but about 10 per cent. were being maintained in institutions. The flgures show that the Poor Law medical officers concerned classified the mental capacity of these defectives as follows: 2.3 per cent. as moral imbeciles, 5.5 per cent. as idiots, 15.4 per cent. as ordinary imbeciles, 44.5 per cent. as feeble-minded, and 32.3 per cent. as mentally infirm. When the figures relating to those under the age of 60 are compared with those obtained by the Local Government Board in 1905, and by the Royal Commission on the Care and Control of the Feeble-minded in 1906, there would appear to have been a large increase in the intervening years, but the compiler of the return is of opinion that this is not really the case, the apparent increase being largely due to the wider scope of the subheads under which information was sought on the present occasion. These subheads were those employed and defincd in Clause 17 (2) of the Mental Deficiency Bill as introduced in 1912. In the Mental Deficiency Bill of the current year the definitions are somewhat modified, and the classiflcation excludes mentally infirm persons, that is to say, "persons who through mental infirmity arising from age or the-decay of their faculties are incapable of managing themselves or their affairs.' . These are the main points brought out by the return, the greater part of which is devoted to tables showing the precise distribution of defectives throughout the country.

\section{The Science Committée}

OF THE

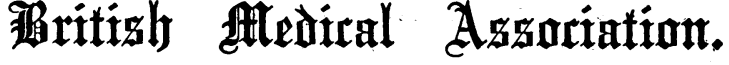

\author{
ON THE
}

GENERAL TOXIC EFFECT OF HEAVY ME'TAFS AFTER SUBCUTANEOUS INJECTION, AND ON

THE QUESTION OF POISONING BY VOLATILE EMANATIONS FROM PAINTS.:

BY

BENJAMIN MOORE, M.A., D.Sc., F.R.S.,

JOHNSTON PROFESSOR OF BIO-CHEMISTRY, UNIVERSITY OF LIVERPOOL: GEORGE FRANCIS OLDERSHAW', M.D.,

AND

The rate OWEN T. WILLIAMS, M.D., M.R.C.P., IIVERPOOL.

(From the Johnston Bio-chemical Iaboratory, University of Liverpool.

Although it is well known that most of the heavy metals possess closely similar effects when so administered that they reach the general circulation, no systematic attempts to define more accurately comparative lethal doses, sites of action, and paths of elimination made by the same observers experimenting comparatively with several of these metals have, so far as we are aware, been carried out. This task we have undertaken upon different species of animals, and using varying doses of copper, zinc, silver, tin, arsenic, and lead.

Our attention was first attracted to the subject by the relative ease with which trypanosones can be driven out of the general circulation by the organic arsenical compound, atoxyl; while in other animals of a larger type, such as the dog, the donkey, and large draught animals, as also in the human subject, it is much more difficult to produce this effect, and the permanent removal of certain species of trypanosomes is almost impossible in such types of animals, as is shown by the work of Moore, Todd and Nierenstein, ${ }^{1}$ and many other observers.

The reason for this remarkable result, so unfortunate in regard to the practical treatment of trypanosomiasis in man and higher animals by arsenic and antimony, is to be found in the site of attack upon the tissues of the higher animals which are acting as hosts by the heavy metal during the process of excretion.

The immediate effect of the drug upon the parasites depends upon the concentration which can be safely reached in the blood of the host without causing death. On the other hand, the safe limit which can be reached with the host depends on the concentration which can be borne by that type of cells in the body where the drag is adsorbed and accumulated in the process of excretion. These two concentrations do not run parallel in different types of animals, and it is for this reason that the dosage of atoxyl, and, indeed, of any heavy metal, does not vary as the weight of the animal, and hence a concentration of drug sufficient to kill and completely destroy the parasite so that it never reappears can be attained in a rat when it is impossible in a dog or a man.

Experimental observation after a large dose of an inorganic salt of a heavy metal given hypodermically in dilute solution, as also similar investigation after administration of an organic arsenical compound such as atoxyl, demonstrates that the chief site of attack is the intestinal mucosa where there is enormous congestion, and often haemorrhagic patches, or actual haemorrhages into the intestine.

Since the drug by such a method of administration is not brought in high concentration in contact with the intestinal cells, as might be supposed to be the case when it is administered by the mouth, it becomes probable that the drug concentrates there in process of excretion by the * The expenses of this research have been defrayed by a grant from
the British Medical Association. 